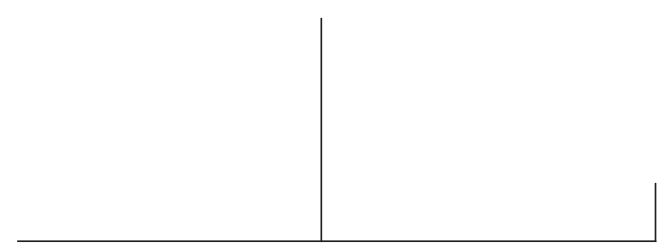

Rev. Latinoam. Psicop. Fund., II, 4, 143-158

\title{
Un caso para la clínica de las psicosis: Vaslav Nijinsky. Un caso paradigmático de la investidura narcisista del cuerpo y del devenir psicótico
}

Nafia Marianne Laurence Bahena Yaghen-Vial

Este articulo subraya la trascendencia de la obra del dios de la danza quien revolucionó la visión que se tenia de la técnica clásica del ballet para convertirse en el padre de la danza moderna.

Nuestro análisis parte desde el núcleo familiar en donde se gesta la locura, al mismo tiempo que es un punto de partida para comprender la transmisión de la danza como un espacio de contención y sublimación de los impulsos de muerte en Nijinsky. Asimismo se aborda su único testimonio escrito en estado delirante. Finalmente se hace mención a la hospitalización.

Palabras llave: Danza, delirio, cuerpo, sublimación 


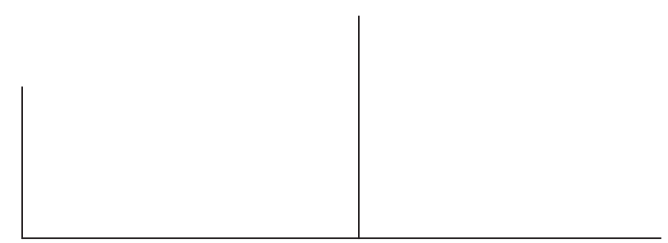

Cuando se habla de Vaslav Nijinsky inmediatamente nos remite a los Ballets Rusos de Diaghilev y a su gran aportación cultural y artística en nuestro siglo. En efecto, mucho de lo que hoy llamamos arte contemporáneo tiene su origen en aquellos jóvenes talentos que Diaghilev reunió para que trabajarán en su Compañía como Anna Pavlova, Támara Karsavina, Igor Stravinsky, Pablo Picasso, Vaslav Nijinsky entre otros; y que ahora han pasado a la historia por sus obras que no han sido igualadas y que siguen influyendo a los artistas contemporáneos. Así como Anna Pavlova continúa siendo el modelo de bailarina a seguir, Stravinsky es el padre de la música contemporánea, Picasso, el fundador del cubismo, de mismo modo la obra de Vaslav Nijinsky es de suma importancia porque es él, el padre de la danza moderna.

A pesar de la importancia y trascendencia del legado artístico de Vaslav Nijinsky para el siglo XX es muy poco lo que se ha escrito sobre él. Generalmente, lo que se ha escrito sobre este bailarín han sido estudios de sus coreografías o bien se ha explotado con gran morbo el hecho de que los últimos treinta años de su vida los viviera sumergido en la locura; salvo el psiquiatra Peter Ostwald quien es una de las pocas personas que ha realizado una investigación seria para elaborar la biografía de este bailarín. Sin embargo, en lo que concierne al psicoanálisis no existe nada y a mi parecer Vaslav Nijinsky es una figura fascinante que abre un sin fin de planteamientos psicoanalíticos que enriquecerían a la teoría psicoanalítica alrededor de la clínica de las psicosis.

\section{Evolución de la esquizofrenia en Nijinsky: génesis y circulación de la locura familiar}

Vaslav Nijinsky nació el 12 de marzo de 1889 en Kiev en una época en la que el arte del Ballet estaba en pleno florecimiento en Rusia y por lo tanto favoreció el desarrollo del talento innato de este bailarín. Por otra parte, sus padres siendo ambos bailarines profesionales impulsaron en este campo a sus tres hijos: Stanislav, Vaslav y Bronislova. Desde muy temprana edad les fomentaron la danza como una actividad natural haciéndolos participar en 


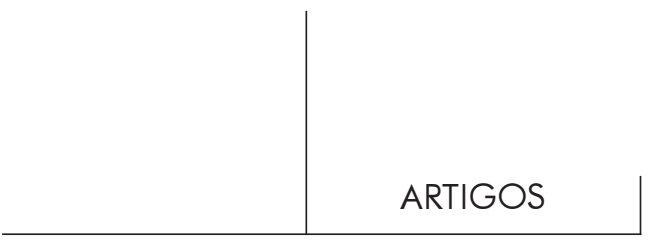

diferentes espectáculos para así prepararlos a una futura carrera de artistas. Sin embargo, esta iniciación tan precoz e intensiva a la danza y una serie de eventos trágicos en la vida de Nijinsky parecen haberle provocado una desventaja en otros dominios como son el desarrollo intelectual y social pues creció en el seno de una familia donde subir a escena y gustar al público eran más importantes que otros logros, incluso en detrimento de los lazos afectivos estrechos; que finalmente culminaron en un ataque esquizofrénico de catatonia lo cual muestra la incapacidad misma al movimiento y a la expresión.

En el caso de Vaslav Nijinsky, el origen de su locura parece remontarse incluso antes de su nacimiento, situación que remite a lo que Piera Aulagnier escribe con respecto al conflicto psicótico en Un interprète en quête de sens, el cual lo sitúa incluso dos generaciones anteriores y que serán decisivas en el devenir del sujeto.

Todo sujeto viene a ocupar un lugar en el mito familiar: este mito, cuya importancia nos es demostrada, tan necesaria resulta, por el lugar que mantendrá en el fantasma fundamental, pues le asigna, en la tragicomedia de su vida, un papel que determina con anterioridad las replicas de los partenaires. ${ }^{1}$

Es necesario en un primer tiempo presentar brevemente la historia de la madre y del padre de Vaslav Nijinsky con el propósito de poder situar el origen de algunos traumas que inconscientemente le fueron transmitidos a Vaslav Nijinsky y que finalmente desembocaron en un quiebre psicótico.

Eleonora Nicolaevna Bereda, madre de Vaslav Nijinsky, nace en Varsovia, Polonia. Su infancia fue compleja y traumática, a la edad de siete años queda huérfana cuando su padre, sumergido en la depresión por haber perdido todo en el juego, muere de un "paro cardiaco" y poco tiempo después pierde también a su madre, presa de un duelo patológico el cual consistió en rechazar toda clase de alimento para así dejarse morir de hambre. Desdichada en su hogar, Eleonora se volvió una persona muy temerosa que en su hermana Estefanía halló un figura materna para refugiarse al grado de apropiarse también del deseo de ésta, es decir, convertirse también en bailarina. Frente a la hostilidad y oposición de sus hermanos con respecto a ser bailarinas, las dos hermanas abandonaron su hogar y se inscribieron en la Escuela de Ballet de Varsovia.

Estos traumas infantiles de Eleonora constituyeron esa "dimensión histórica maternal" a la que se refiere Piera Aulagnier como un elemento fundamental para la estructura psíquica y en la manera de transmitir las figuras fundamentales para constituirse como sujeto. En efecto, una vez que fuese madre estos desastres infantiles tuvieron consecuencias catastróficas en lo que respecta a la transmisión inconsciente de estos hechos a sus hijos como por ejemplo: el recuerdo que mantuvo 


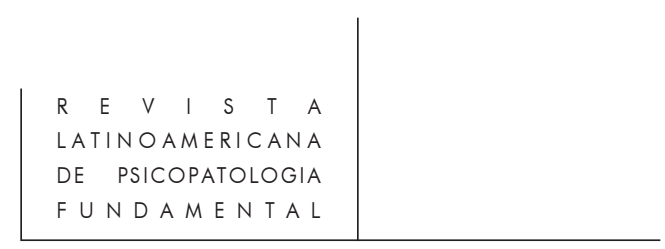

de la muerte de su padre se perpetuo a través de su hijo Vaslav quien padeció toda la vida una terrible angustia frente a las enfermedades del corazón; otra transmisión que se remonta a la muerte de su padre, una vez más en su hijo Vaslav fue aquella tendencia a reaccionar frente a las frustraciones ya sea con arranques de furia o bien con depresiones muy fuertes.

Eleonora tenia doce años y con su hermana eran las dos bailarinas mas jóvenes de la Compañía. Cuando tenia 19 años, después de siete años bailando y viajando, decidió que quería instalarse en un lugar fijo y abandonar su carrera de bailarina para poder casarse con un oficial de artillería ruso de quien estaba enamorada. Sin embargo, pocos días antes de la boda, mientras que pasaban por Varsovia, su comprometido se expreso con desprecio de los polacos y de cuan orgulloso se sentía del dominio que ejercía Rusia sobre Polonia. Eleonora al oír estas palabras permaneció muda (aguantar el sufrimiento en silencio se convertirá en una característica familiar) y poco después decide romper el compromiso para volverse a incorporar a la Compañía de Ballet.

No es ocho años más tarde que Eleonora de 27 años de edad conoció a un hombre, también bailarín como ella, con el cual finalmente acabó casándose. Ese hombre fue Thomas Lavrentievitch Nijinsky quien tenia 22 años y era también polaco. Nacido en Varsovia, provenía de una familia de revolucionarios. Su abuelo (un antiguo terrateniente que había perdido sus tierras) y su padre (empleado de los ferrocarriles) eran colaboradores en los ataques anti rusos. Desde los 8 años de edad Thomas había roto con la tradición familiar porque siempre se había sentido inclinado por el teatro y su deseo era convertirse en bailarín.

Cuando Thomas Nijinsky obtuvo su Diploma en la Escuela de Teatro de Wielki, la escuela más prestigiada en Polonia por sus artistas de espectáculos, decidió irse a trabajar a Rusia, porque los bailarines formados en Polonia eran los más buscados. Thomas era un joven, alto y de semblante varonil, muy admirado por su fuerza y sus cualidades atléticas. Podía realizar saltos cuya altura no eran usuales y tenía muchos atributos como actor, posteriormente Vaslav Nijinsky heredó estos atributos de su padre. Al mismo tiempo, desde el plano afectivo, Thomas Nijinsky parecía inmaduro, y tenía fama de ser irrespetuoso, entiéndase con ello violento.

Asimismo, la historia de amor de los padres de Nijinsky muestra algunos antecedentes importantes de lo que constituyó la vida familiar que formaron como pareja, caracterizada por los arrebatos de violencia de Thomas Lavrentievitch Nijinsky. Es en Rusia donde Eleonora conoció a Thomas quien era cinco años menor que ella. Cuando Thomas conoció a Eleonora, éste tenia 20 años y desde entonces ya le formulaba propuestas de matrimonio las cuales ella rechazaba aún si le gustaba pues le inspiraba temor y por lo tanto ponía como pretexto las diferencias de edad entre ellos. Sin embargo, el relato que existe sobre la última y definitiva petición de mano de Thomas a Eleonora fue: "Un día, sacó un revolver declarando que era la 


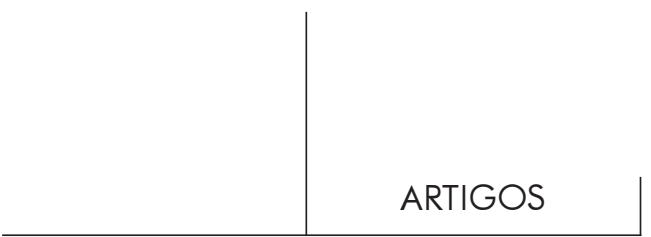

última vez que le pedía matrimonio. Por temor a que la lastimara, o que él se lastimara, ella aceptó"2 muestra el establecimiento de un carácter paradójico del amor en la familia Nijinsky-Bereda alrededor de la muerte como un modelo natural del amor.

Es importante señalar que en ambas historias el papel que tiene el Ballet en su devenir es decisivo pues les permitió a ambos huir de un destino familiar. En el caso de Eleonora, el ballet funge como una protección con relación al medio circundante: huir de su casa en la cual no era feliz pues no tenía una buena relación con sus hermanos; también como un refugio frente al sufrimiento que desembocó la ruptura de su compromiso con el oficial ruso donde el Ballet fue su cómplice para expresar aunque no en palabras su sentir. Mientras que en el caso de Thomas Nijinsky, el Ballet fue una forma de rebelarse contra la tradición familiar del orden de lo bélico aunque también en el Ballet encontró una manera de exteriorizar, de canalizar su pasión creando una técnica atlética que más tarde se convirtió en una fuente de admiración y de inspiración para sus hijos, destacando Vaslav Nijinsky.

No cabe duda que esa pasión por el Ballet por parte de Thomas Nijinsky y la sensibilidad de Eleonora Bereda serán decisivas en la carrera de Vaslav Nijinsky; sólo que a diferencia de sus padres el Ballet para Vaslav Nijinsky será su única razón de ser.

A esta dinámica familiar se une los eventos traumáticos que se dieron especialmente como fue el de su hermano mayor Stanislav que a la edad de siete años fue víctima de un accidente saltando por la ventana quedando "retrasado mental", al grado de ser internado en un hospital psiquiátrico en San Petersburgo hasta su muerte en 1918. Este evento que introdujo el espectro de la locura en la familia contribuyó quizás en hacer nacer en Nijinsky un sentimiento de angustia frente a los trastornos mentales, al igual que una tendencia por imitar a los “desequilibrados" como lo podemos leer en sus Cuadernos:

Yo sé que todo el mundo dirá: "Nijinsky se ha vuelto loco", pero me da igual, porque yo ya he interpretado al loco en la casa. Todo el mundo lo pensará, pero no me meterán en una casa de locos, porque yo bailo muy bien y doy dinero a todos aquellos que me piden. La gente ama a los excéntricos, es por eso que me dejaran tranquilo, diciendo que soy un payaso loco. Amo a los locos, porque sé hablarles. Cuando mi hermano estaba en su casa de locos, yo lo quería, y el me sentía. Sus amigos me querían. En la época, tenía dieciocho años. Yo entendía la vida de los locos. Yo conozco la psicología de un loco. Yo no contradigo los locos, es por esto que los locos me quieren. Mi hermano murió en un asilo de loco. ${ }^{3}$

2. P. Ostwald. Nijinsky ou Un saut dans la folie, p. 22.

3. V. Nijinsky. Cahiers, version non expurgée traduite du russe par Christian Dumais-Lvowski et Galina Pogojeva, p. 34. 


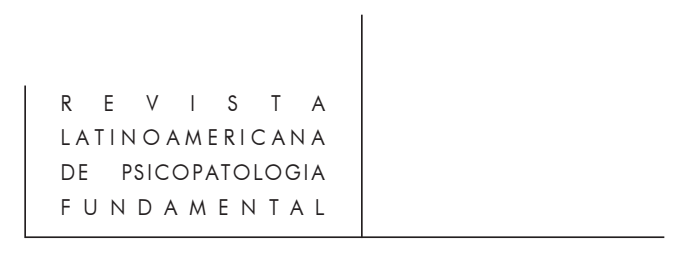

A esta tragedia, es necesario añadir la crisis conyugal de sus padres que concluirá con el abandono por parte del padre por otra bailarina. Este episodio tendrá varias consecuencias contradictorias. Por una parte, Nijinsky siendo todavía un niño se verá forzado a asumir el lugar de jefe de familia con todas las obligaciones que implican este rol al mismo tiempo que en él se depositaran todos los cuidados y el amor sobreprotector de su madre configurando así una situación edípica. Este abandono paterno marca también otro aspecto fundamental en la constitución psíquica de Nijinsky que consiste en la ausencia de una figura paterna. Este abandono le despojo de un padre a quien amar y tomar como modelo de bailarín. Posteriormente profesores, amantes y en especial Diaghilev tomaran el papel fallido del Padre. Esto tendrá fuertes implicaciones en aquello que Lacan propone como el Nombre del Padre. Cabe señalar que la única vez que Nijinsky mencionará en sus Cuadernos a su padre es para evocar un accidente en el que estuvo a punto de morir ahogado, cuando su padre intentaba enseñarle a nadar y lo avienta al Neva. Esta escena es descrita como un evento traumático en los Cuadernos durante su caída en el estado psicótico:

Yo era un niño, y mi padre quiso enseñarme a nadar. Me aventó al agua, allí donde nos bañábamos. Yo caí y me hundí hasta al fondo. Yo no sabía nadar, pero sentí que me faltaba el aire, entonces yo cerré la boca. Yo tenía poco aire, pero yo lo conservaba pensando que si Dios lo quería, yo sería salvado... De repente, yo sentí una fuerza física y yo brinqué. Cuando yo brinqué, yo percibí una cuerda. Yo me aferré a la cuerda y yo estaba salvado. Yo digo lo que me sucedió. Usted puede preguntarle a mi madre, si ella no ha olvidado esta historia que sucedió en un baño para hombres en el Neva, en Petersburgo... Tan sólo era un niño de seis ó siete años y yo no he olvidado esta historia, es por eso que busco darle una buena impresión a mi pequeña hija, porque yo sé que un niño no olvida lo que le ha sucedido. El Doctor Franquee me ha dicho que no debiera hacerle algo malo a Ira, porque un niño no olvida las cosas que hicieron su padre y su madre. Me contó que una vez su padre se había enfurecido contra él y hasta ahora no había podido olvidar esta furia. El Doctor Franquee hizo una mueca, y yo sentí la ofensa hecha por su padre... Yo comprendí que el niño había perdido el amor de su padre y el padre había perdido el amor de Dios. ${ }^{4}$

Este párrafo considero que es fundamental para el análisis de la problemática del Nombre Padre en Nijinsky pues representa esa dinámica paradójica en la cual el Padre es esa figura que conjuga amor y odio al mismo tiempo que es detentora de poder que puede ser incluso tiránico que niega al sujeto porque puede decidir sobre la persona de Nijinsky como si éste fuese una marioneta.

4. Ibidem, p. 131. 


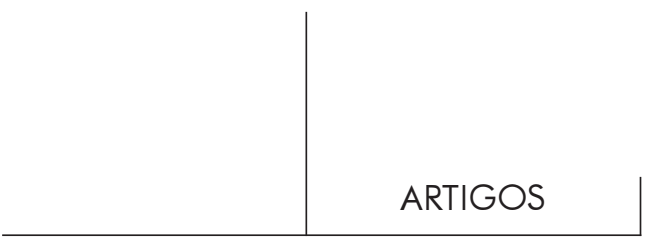

Todo este conjunto de tragedias es crucial en la vida de Nijinsky porque a partir de estos dolores frente a las cuales fue incapaz de elaborarles un duelo, contribuyendo a reforzar aquella convicción transmitida por su madre en el sentido de que se debe soportar el dolor en silencio incrementando su tendencia a ocultar sus sentimientos y a huir de los conflictos. Este impedimento de llevar a cabo el duelo a todos estos sufrimientos los fue arrastrando a lo largo de su vida. Sólo la danza fue el medio que le permitió sublimar, expresar y contener sin la mediación de la palabra, toda esta cadena de sufrimientos. Una vez privado e ignorado del contexto artístico de la danza, Nijinsky intentó por medio de la escritura delirante de sus Cuadernos (al igual que la obra de Schreber), una manera de mantener la estabilidad psíquica; lo cual a su vez fue un testimonio de su decadencia psíquica que finalmente terminó en un quiebre psicótico que lo llevó al hospital psiquiátrico el resto de sus días

\section{Algunos puntuaciones sobre la constitución psicosexual en Nijinsky}

Los prejuicios represivos que condenaban la masturbación pues se creía que hacía daño a la salud, la homosexualidad considerada como un pecado, incluso un crimen y la creencia frecuente en los bailarines según la cual el onanismo podía debilitar al organismo han de haber contribuido en acentuar en Nijinsky la idea que la sexualidad es algo horrorizante y contradictoria lo cual incrementó su confusión patológica.

El sentimiento de culpabilidad ligada a la actividad sexual estuvo en el origen de graves problemas psíquicos en Nijinsky durante varios años. En gran parte estos traumas son atribuibles a la actitud sobreprotectora de su madre que desaprobaba el interés de Vaslav por las mujeres hasta mantener una posición cómplice en lo referente a la relación homosexual de su hijo con el Príncipe Lvov. Esta relación era una verdadera bendición porque representaba para ella, la solvencia económica que no existía desde la ausencia del padre y que siempre había faltado a sus hijos, pero en Lvov también veía un aliado seguro para evitar que Vaslav se convirtiera en un corredor de faldas como su padre, poniéndolo también alerta varias veces contra las relaciones con las mujeres de "mala vida" a causa de las enfermedades venereas. Desgraciadamente, Nijinsky sintiéndose rechazado por Lvov pues lo había cedido a otros amantes, no tardó en atraerse algunos problemas, una blenorragia, confirmando las predicciones de su madre acentuando su hypocondrismo. El recuerdo que conservó de esta experiencia traumática muestra la sobre-investidura del órgano:

Yo lloraba. Yo sufría. Yo no sabía qué hacer. Iba con el doctor, pero el no hacía nada. Me dijo de comprar una jeringa y unos medicamentos. Me dijo de inyectar el 


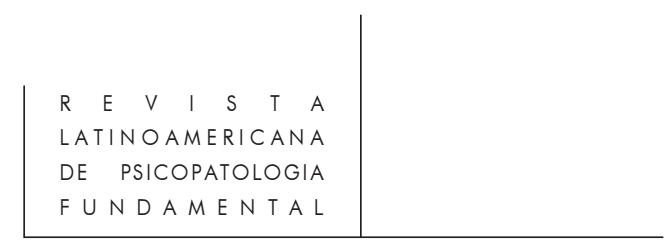

medicamento en mi miembro. Yo lo inyectaba. Yo hundía la enfermedad más profundamente. Yo noté que mis testículos se hinchaban. ${ }^{5}$

En este sentido puede ser útil lo que Freud señala en la "XXIV Conferencia de introducción al psicoanálisis" con respecto al fenómeno de la modificación corporal (del cuerpo físico) en el cual se produce la incursión en la enfermedad de tipo orgánica que desencadena, automáticamente, en el cuerpo psíquico y instaura el fantasma que se traduce en un síntoma:

No es raro [en ellas] que una alteración patológica del cuerpo - por inflamación o una herida quizás - despierte el trabajo de formación de síntoma, que convierte con rapidez ese síntoma que la realidad le procura en subrogado de todas aquellas fantasías inconscientes que acechaban la oportunidad de apropiarse de un medio de expresión. ${ }^{6}$

En lo que concierne su carrera artística, el encuentro con el Príncipe Lvov y la aristocracia de San Petersburgo es decisiva en la vida de Nijinsky porque le permitió relacionarse con Serge de Diaghilev, dieciocho años mayor, un hombre vanguardista que supo explotar el carisma de Nijinsky para hacer de él, el bailarín estrella de su Compañía: Los Ballets Rusos. En sus Cuadernos, la relación patológica entre la madre y su homosexualidad mal asumida se presenta bajo una connotación de sacrificio. En efecto, la idea de que su madre pudiera morir de hambre si él no se hacía cargo de ella lo atemorizaba siendo un motivo suficiente para despertar en él angustia. Prueba de ello es lo que escribe en sus Cuadernos:

Lvov me presentó por teléfono a Diaghilev, quien me hizo ir al Hotel Europa donde el vivía. Yo lo detestaba por su voz demasiado segura, pero fui a probar suerte. Allí yo encontré la suerte, porque lo amé enseguida. Yo temblaba como una hoja. Yo temblaba como una hoja. Yo lo detestaba, pero yo fingía, porque sabía que mi madre y yo moriríamos de hambre. ${ }^{7}$

Situación que remite a esa "dimension historique maternelle" que angustiaba a Nijinsky y que para evitar que se repitiera la historia de su abuela ahora en su madre, estaba incluso capaz de prostituírse con Diaghilev:

Yo comprendí a Diaghilev desde el primer minuto, es por esto que yo fingí estar de acuerdo con todas sus ideas. Yo comprendí que era necesario vivir, es por esta razón que el sacrificio a realizar me daba igual. ${ }^{8}$

5. Ibidem, p. 208.

6. S. Freud. Obras Completas, tomo XVI, p. 356.

7. V. Nijinsky. Op. cit., p. 144.

8. Idem. 


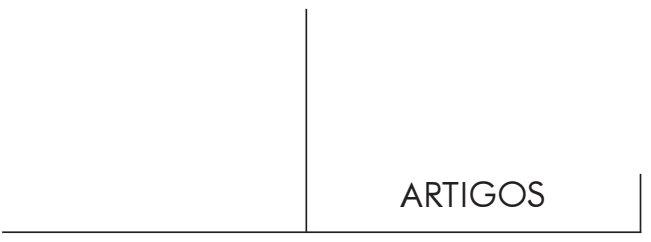

A lo largo de sus Cuadernos, Nijinsky da la impresión que estuviera escribiendo su apología pues se refiere a sus relaciones sexuales como errores de juventud lo que también revela una actitud de culpabilidad:

Yo era joven, es por eso que yo hacía errores. Mis errores, yo siempre quise corregirlos, pero habiendo notado que nadie me querría, fingía ser malo. Yo no amaba a Diaghilev, pero yo vivía con él. ${ }^{9}$

La relación patológica con Diaghilev se caracterizó por una ambigüedad de sentimientos de amor-odio. En algunos momentos, Diaghilev encarna el papel del amo tiránico que tiene el poder y la ley para manipular a Nijinsky reducido al estatuto de objeto. En otras ocasiones Diaghilev constituye en la vida de Nijinsky una figura paterna digna de su amor y admiración. Por ello Diaghilev constituye esa figura paterna en la que se centra todo el poder fálico.

Yo detesté a Diaghilev desde los primeros días de nuestro encuentro, porque yo conocía el poder de Diaghilev, pues abusaba de su poder. Yo era pobre. Yo ganaba 75 rublos por mes. 75 rublos por mes no eran suficientes para nutrirnos, mi madre y yo. ${ }^{10}$

En efecto, siempre y cuando Nijinsky permaneciese sometido a la ley impuesta por Diaghilev obtendría a cambio seguir permaneciendo en la gloria como bailarín estrella de los Ballets Rusos. Por lo que en este tipo de relación se puede deducir que había algo del orden del goce que se jugaba entre los dos partenaires. Una vez que Nijinsky no obedeció más la ley impuesta por Diaghilev, al contraer matrimonio con Romola Pulszky, este último aplicó todo su poder para hundir a Nijinsky despidiéndolo de su Compañía. Una vez desamparado sin la protección de Diaghilev y sobre todo sin el esplendor de los Ballets Rusos, Nijinsky trataría a pesar de sus circunstancias de montar su propia compañía y escuela de Ballet, lamentablemente serán puros intentos fallidos que más tarde lo conducirán al desencadenamiento de su locura.

Por último es importante señalar la relación delirante que Nijinsky mantuvo con la carne porque ésta, según él, constituye un alimento que debe ser prohibido porque lo vincula con el sexo. En efecto, Nijinsky en su delirio sostiene que el consumir carne despierta y excita la lujuria. Esta idea lo angustia porque la lujuria para él significaba la muerte. En sus Cuadernos escribe:

Hoy, yo comí carne, y he sido invadido de un deseo por una mujer de la calle. Yo no amaba a esta mujer, pero la lujuria me incitaba hacia ella. Yo quería hacerle el amor, pero Dios me contuvo. Yo tengo miedo de la lujuria, pues yo conozco su sentido. La lujuria es la muerte de la vida. ${ }^{11}$

9. Idem.

10. Ibidem, p. 142.

11. Ibidem, p. 44. 


\section{La danza como espacio del ser}

Nuestros padres eran artistas de ballet, bailarines. Nosotros nacimos artistas de la danza. Naturalmente nosotros aceptamos este patrimonio proveniente de nuestros padres - nuestros cuerpos de bailarines. El teatro y la danza fueron desde nuestro nacimiento un modo de vida natural. En el teatro, nosotros estabamos en nuestro elemento natural, cada cosa hallaba un eco en nuestra alma. ${ }^{12}$

En Vaslav Nijinsky, ese estatuto de la danza representa un factor contundente en su organización psíquica, pues la danza se estableció como una dimensión del ser puesta en practica. Desde niño se caracterizó como alguien sumamente introvertido con grandes dificultades de expresar en palabras sus sentimientos y pensamientos. Sólo la danza le permitía descargar toda su energía y expresividad. Su expediente en la Escuela de los Teatros Imperiales lo describe como un niño tímido que presenta signos de gran fragilidad emocional, de salud débil y de parecer "retrasado" a causa de sus resultados escolares mediocres. Además, Vaslav tenía grandes dificultades de elocución provocando que hablase con vacilación, aprehendiendo las reacciones que suscitaba en sus interlocutores. Este verdadero obstáculo era todavía acentuado por su físico inhabitual que hacía de él seguidamente objeto de burla. En consecuencia, estas experiencias para un niño tan sensible como lo era Nijinsky han debido ser traumáticas; contribuyendo a aumentar su inseguridad, su aislamiento social y reforzar el síntoma familiar del silencio como una defensa para afrontar el sufrimiento. De esta manera se podía ubicar a la danza como un espacio donde la sublimación constituye un destino pulsional.

La danza es el medio privilegiado de expresión en Nijinsky. A manera de hipótesis, se puede establecer que la danza es un lenguaje no verbal; en donde la música reemplaza la palabra y se establece como limite. En este limite el bailarín transmite la esencia de la obra por medio de sus gestos y su movimiento corporal. Esta conformación del espacio de la danza y sus límites fue probablemente lo que permitió a Nijinsky tener un efecto de contención en cuanto a su estructura psíquica.

Las palabras para el bailarín son limitadas y de todos modos en el arte de la danza la palabra es de más, quiere decir que para poder plazar la palabra hay realmente que tener conocimiento de música, de movimiento... ${ }^{13}$

De esta manera, la danza en Nijinsky era la posibilidad de sublimar aquellos eventos traumáticos por medio de los personajes y las coreografías que bailó y escribió encontrando así un destino pulsional a su dinámica psíquica. Una

12. B. Nijinska. Mémoires 1891-1914, p. 19.

13. Entrevista realizada por Marianne Bahena à Mariala Palacio, coreógrafa argentina. Paris, julio 1998. 


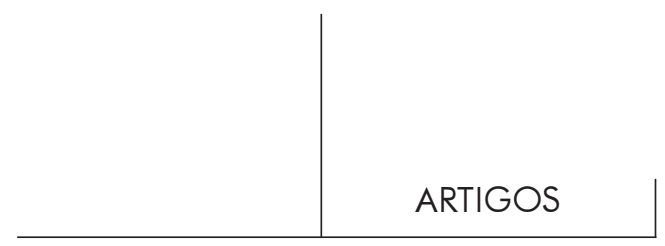

característica esencial en Nijinsky es que bailó a personajes andróginos. Estos personajes representan sus propias "ilusiones sin cuerpo" (en el sentido descrito por Assoun al referirse al mito de Narciso en su obra Introducción a la metapsicología freudiana), entre los cuales los más importantes son los que forman parte de los tres Ballets que lo consagraron como el Dios de la Danza es decir, Petrouschka (1911), Le spectre de la rose (1911), y L'après-midi d'un faune (1912). Cada uno de estos ballets son fundamentales para el análisis del investidura narcisista del cuerpo en Nijinsky ya que los personajes que encarnó fueron: una marionetahumana en Petroushka, un espectro en Le spectre de la rose y un fauno en L'aprèsmidi d'un faune. Esto muestra como Vaslav con su cuerpo "no hacia que uno con este 'objeto' que no es otro que la imagen de su propio cuerpo". ${ }^{14}$ En sus Cuadernos con respecto al fauno escribirá: "El Fauno soy yo". ${ }^{15}$

Cabe señalar la problemática de las psicosis que plantea Lacan en su Seminario III - Las psicosis en donde la estructura psíquica del psicótico muestra la incapacidad metafórica del lenguaje en donde la frase "El Fauno soy yo" implica una literalidad en donde "la proyección que hace retornar del exterior lo que está preso en la Verwerfung, o sea lo que ha sido fuera de la simbolización general que estructura al sujeto". ${ }^{16}$ Le spectre de la rose, Petrouschka y L'après-midi d'un faune representan la dinámica psíquica que se refleja en la personalidad y la obra de Nijinsky. Por ejemplo: En Le spectre de la rose es un ser irreal ni mujer ni hombre que en sus Cuadernos escribirá más tarde: "Yo soy el esposo y la esposa en una sola persona"17, asimismo el último brinco que da por la ventana para salir de escena sublima el accidente de su hermano Stanislav. Petrouschka es una proyección inconsciente de su propio conflicto es decir, el impedimento de relacionarse con el otro. Por último el fauno representa lo idealizado, aquello sin limites con respecto a lo humano con una gran carga de erotomanía.

En el momento en que Nijinsky se asumía como un espectro, una marioneta o un fauno no sólo se encontraba en su elemento natural sino además tenía la posibilidad de establecer, por medio de la danza, un lazo social con el mundo exterior. De esta manera permitía una estabilidad psíquica porque sublimaba sus impulsos inconscientes en su producción.

14. P.L. Assoun. Introduction à la métapsychologie freudienne, p. 172.

15. V. Nijinsky. Op. cit., p. 259.

16. J. Lacan. Seminario III. Las psicosis, p. 73.

17. L. Courtillet et J.-H. Piettre. Nijinsky, p. 65. 


\section{El discurso delirante de los Cuadernos}

Una vez que Diaghilev despide a Vaslav Nijinsky de los Ballets Rusos, este último queda también privado de su campo de expresión, es decir, la danza como escritura corporal en la música. Entre el 19 de enero y el 04 de marzo de 1919, Vaslav Nijinsky en un estado maníaco redacta los cuatro cuadernos que constituirán el libro que él habría intitulado El sentimiento cuyo propósito según Nijinsky es "explicar a la gente las costumbres que hacen morir el sentimiento"18. Cabe señalar un aspecto importante con respecto a la producción de su libro que revela un temor narcisista de quedar expuesto a ser completamente borrado:

... yo quiero que fotografíen mis escritos para explicar mis escritos, porque mi escritura es la de Dios" en vez de imprimirlos, "porque la impresión destruye la escritura. La escritura es algo bello, es por eso que es necesario fijarla". ${ }^{19}$

Los Cuadernos de Nijinsky constituyen el testimonio del quiebre psicótico, en el cual por medio de la escritura intentó sostener el Yo que perdía su consistencia en la entrada a la psicosis, perdiendo ese movimiento que le brindaba un equilibrio en su estructura psíquica:

Yo soy un hombre malo. Yo no amo a nadie. Yo deseo daño a todo el mundo y bien para mí-mismo. Yo soy egoísta. Yo no soy Dios. Yo soy una bestia feroz. Yo me masturbaré y haré espiritismo. Yo devoraré todos aquellos que caigan bajo mi mano. Yo no me pararé frente a nada. Yo amaré la madre de mi mujer y mi hija. Yo lloraré, pero yo haré todo lo que Dios me ordené. Yo sé que todo el mundo tendrá miedo de mi y que me encerraran en una casa de locos, pero no me importa. Yo no tengo miedo a nada. Yo deseo la muerte. Yo me dispararía una bala en la cabeza si Dios desea todo esto para el mejoramiento de la vida, es por eso que yo soy su instrumento. ${ }^{20}$

En este extracto podemos señalar el uso exhaustivo del pronombre personal "yo" (17 veces) el cual puede representar ese intento maníaco de contener su locura y de establecer una relación con el Otro para sostener su Yo. En el transcurso de la escritura se presenta una disolución narcisista en la cual la dimensión simbólica fallaba, instalándose así la forclusión como mecanismo en el cual las formaciones delirantes gobiernan su estructura discursiva.

En el momento en que se excluye la posibilidad de un lazo social, Nijinsky establece un lazo fusional delirante con Dios que comienza con un "Dios está en mi y yo estoy en Dios". ${ }^{21}$ Este referente omnipotente deviene una pérdida de sus

18. V. Nijinsky. Op. cit., p. 86.

19. Ibidem, p. 67.

20. Idem.

21. Ibidem, p. 199. 


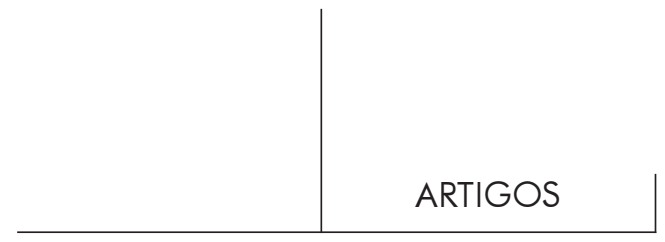

limites narcisistas que puede ser percibido cuando escribe: "Yo comprendo la gente, y yo estoy triste de confesarlo, pero yo debo decir que es la verdad. Yo no soy más un hombre, pero Dios". ${ }^{22}$ Esta relación con su imagen delirante de Dios va estableciendo diferentes posiciones de Nijinsky. A veces Nijinsky es Dios, otras Dios lo gobierna y en otras el es un instrumento. Esto muestra además el carácter de objeto en el que se asume frente a esta figura. Asimismo, Nijinsky se asume en el rol de un predicador que Dios ha elegido para realizar una misión que consiste en realizar un testimonio que será "una fuente de enseñanza para la humanidad" sobre el sentimiento, el sentir y el resentir pues escribe:

... toda la gente posee el sentimiento. Yo quiero escribir este libro, porque yo quiero explicar lo que es el sentimiento, pero yo sé que esto no es verdad, porque este aviso proviene de las ordenes de Dios. Yo soy un hombre que, como Cristo, ejecuta las ordenes de Dios. ${ }^{23}$

Mientras que otras veces literalmente se asume como Dios. Esta encarnación de Dios implica una pérdida de limite y una disolución del Yo y con ella se presenta la aparición del doble.

Yo quiero firmar Nijinsky para la publicidad pero mi nombre es Dios. Yo amo Nijinsky, no como Narciso, pero como Dios. Yo lo amo porque el me dio la vida. Yo no quiero hacer cumplidos. Yo lo amo. Yo conozco sus costumbres. El me ama, porque el conoce mis costumbres. Yo no tengo costumbres. Nijinsky es un hombre con culpas. Es necesario escuchar Nijinsky, porque el habla por la boca de Dios. ${ }^{24}$

El sobrenombre que tenía Nijinsky, "el payaso de Dios" apunta de nuevo hacia esa forclusión que conlleva la incapacidad metafórica del lenguaje en donde Nijinsky encarna literalmente a ese objeto perseguidor. En los episodios de pleno delirio podemos observar que su Yo está disuelto, sin limite y se manifiesta esa relación entre amo y esclavo, es decir entre su Dios y él, pero que al estar operando la forclusión aparece en lo real. Nijinsky vuelve a actuar el papel de una marionetahombre como en Petrouschka en donde debe cumplir el deseo del Otro que lo gobierna:

Dios me dijo: "Regresa a tu casa y dile a tu mujer que estás loco". Yo comprendí que Dios deseaba mi bien, es por eso que yo fui a la casa con la intención de anunciarle esta noticia. ${ }^{25}$ 


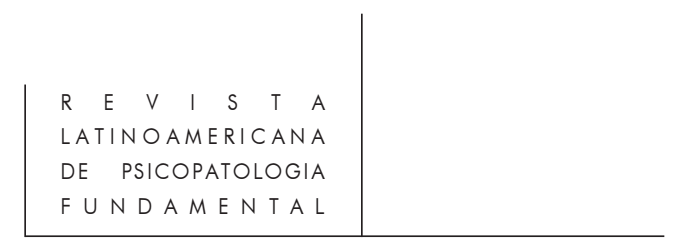

Podemos señalar otra característica de la estructura psíquica de las psicosis que señala Lacan con respecto a la dinámica del amo y el esclavo:

El (Dios) me dijo de acostarme en la nieve. Me acosté. Me ordenó de quedarme acostado por mucho tiempo. Así permanecí hasta que sentí el frío en mi mano. Mi mano comenzó a helar. Retiré mi mano diciendo que no era Dios, me dolía la mano. Dios estaba contento, y me ordenó de regresar, me ordeno de acostarme de nuevo en la nieve, cerca de un árbol. ${ }^{26}$

Asimismo otra característica de la estructura psicótica según Lacan es claramente observable cuando Nijinsky ya no reconoce su cuerpo como una totalidad sino como un cuerpo fragmentado en la cual su mano la asume como un instrumento separado y útil para escribir sus Cuadernos: "Yo quiero escribir, pero mi mano muere, ya que ella no quiere obedecerme". ${ }^{27}$

\section{La hospitalización}

Sin embargo, la escritura de sus Cuadernos no logran contener la decadencia psíquica de Nijinsky. Su familia decide llevarlo a Zurich, viendo la ineficacia del tratamiento realizado por el doctor Franquee. Bleuler diagnostica una "confusión mental de naturaleza esquizofrénica, acompañada de una ligera excitación maníaca"28 cuya hospitalización no es necesaria. A su parecer Nijinsky podría incluso continuar su carrera todavía durante un tiempo, o bien vivir en el hospital donde podría trabajar sus coreografías y ser al mismo atendido al grado quizás de poder sanar de su estado psicótico. De esta forma precipitada, Bleuler realizó el diagnostico de Nijinsky lo cual puede ejemplificar lo que Pierre Fédida señaló en el curso teórico del DEA (1997-1998 ) en la Universidad París 7 en el sentido que el diagnostico es algo que el paciente va, paulatinamente, revelando a lo largo de su análisis donde la escucha del analista es el elemento clave para que en un tiempo a posteriori pueda (sin forzar modelos nosológicos de la clínica) formular un diagnostico especifico sobre el paciente que devendrá la posible dirección de la cura.

En el caso de Nijinsky, sus Cuadernos también juegan un papel relevante en el establecimiento del diagnóstico a priori llevado a cabo por Bleuler sobre su estado. Después de una crisis de cólera, Nijinsky es vuelto a llevar al hospital psiquiátrico Burghölzli en el cual permaneció 48 horas. En ese transcurso de tiempo, Bleuler junto con otros psiquiatras examina los Cuadernos con el fin de tener un

26. Idem.

27. Ibidem, p. 40.

28. Ibidem, p. 16. 


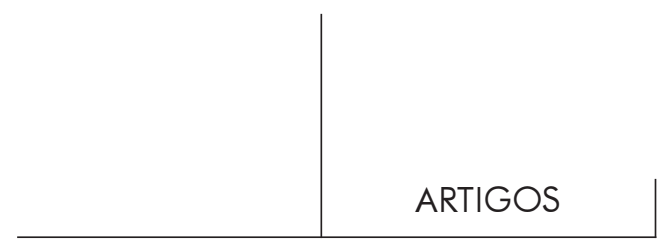

conocimiento de causa del caso para así luego estimar imprudente la opción de dejar solo Nijinsky con su familia. Es a la edad de treinta años que Nijinsky será internado en el hospital Bellevue en Kreuzlingen. En 1938, Nijinsky es tratado a base de insulina. Bleuler quien en esa época ya no ejerce dirá a Romola Nijinsky el día que provocaron el primer choque insulínico en Nijinsky:

Mi querida señora Nijinsky, tuve, hace algunos años, la cruel tarea de anunciarle que, según los conocimientos médicos de la época, su marido padecía una locura incurable. Ahora estoy contento de poder volverle a dar alguna esperanza. Mi joven colega - y tomó la mano de Sekel - a descubierto un tratamiento sobre el cual hice durante cuarenta años investigaciones en vano. Estoy orgulloso de él. ${ }^{29}$

Una vez más se equivocó Bleuler. Nijinsky muere después treinta años de reclusión psiquiátrica en Londres.

\section{Bibliografía}

Assoun, Paul-Laurent. Introduction à la métapsychologie freudienne. Paris: PUF, 1993.

Aulagnier, Piera. Un interprète en quête de sens. Paris: Payot, 1991.

Courtillet, Laurence et Piettre, Jean-Hugues. Nijinsky. Paris: Musée-Galérie de la Seita, 1989.

Lacan, Jacques. Seminario III. Las psicosis. Buenos Aires: Paidós, 1993.

NiJinska, Bronislova. Mémoires 1891-1914. Paris: Ramsay, 1983.

NiJINSKy, Vaslav. Cahiers, version non expurgée traduite du russe par Christian DumaisLvowski et Galina Pogojeva. Canada: Actes du Sud, 1995.

Ostwald, Peter. Nijinsky ou Un saut dans la folie. Paris: Passage du Marais.

Freud, Sigmund. Obras Completas. Buenos Aires: Amorrortu, tomo XVI.

Turi, Ana Maria. Nijinsky, l'invention de la danse. Paris: Félin, 1987.

\section{Resumos}

Este artigo assinala a transcendência da obra do deus da dança, aquele que revolucionou a visão que se tinha da técnica clássica do balet para se transformar no pai da dança moderna.

Nossa análise parte do núcleo familiar onde se gesta a loucura, ao mesmo tempo que é um ponto de partida para compreender a transmissão da dança como um espaço de contenção e sublimação dos impulsos de morte en Nijinsky. Mesmo assim, é abordado seu único testamento escrito em estado delirante. Finalmente faz-se menção à hospitalização.

Palavras-chave: Dança, delírio, corpo, sublimação

29. A.M. Turi. Nijinsky, l'invention de la danse, p. 208. 


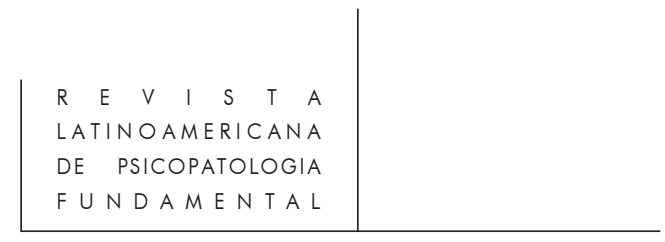

Ce article signale la transcendance de l'oeuvre du dieu de la dance, qui a révolutioné la vision qu'on avait de la technique classique du balet pour se transformer au père de la dance moderne.

Notre analyse part au noyau familier où se donne la gestation de la folie, à la fois qui est un point de départ pour comprendre la transmission de la dance comme un espace de maintien et sublimation des pulsions de mort dans Nijinsky. Tout de même, est abordée son seul testament écrit sur l'état délirant. Finalement on parle de l'hospitalisation.

Mots cles: Dance, delire, corp, sublimation

This paper underlines the transcendent deed of the dance's God, that one who has revolutionized the view one had over the Classical ballet to become the father of the contemporary dance.

Our analysis stems from the family core that is both where the madness is raised and the starting point for the knowledge about the transmission of the dance craft as a containing and sublimating space for the Nijinsky's death impulses. Here we deal with the dancer's will written in a state of delusion and we finally mention his hospitalization.

Key words: Dance, delusion, body, sublimation 